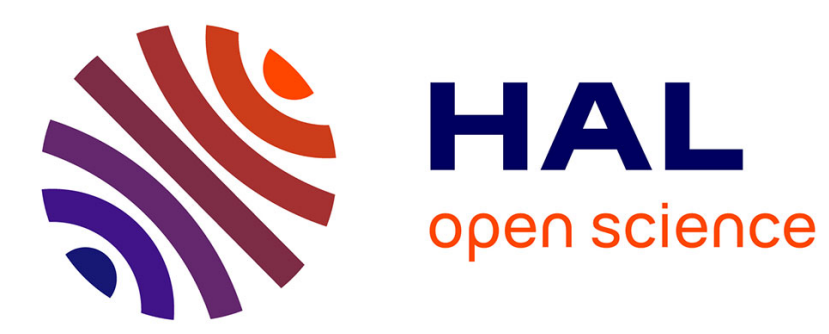

\title{
NOISE AND DIFFUSION IN p-TYPE SILICON
}

\author{
J.-P. Nougier, A. Moatadid, J. Vaissiere
}

\section{To cite this version:}

J.-P. Nougier, A. Moatadid, J. Vaissiere. NOISE AND DIFFUSION IN p-TYPE SILICON. Journal de Physique Colloques, 1988, 49 (C4), pp.C4-165-C4-168. 10.1051/jphyscol:1988433 . jpa-00227931

\section{HAL Id: jpa-00227931 https://hal.science/jpa-00227931}

Submitted on 1 Jan 1988

HAL is a multi-disciplinary open access archive for the deposit and dissemination of scientific research documents, whether they are published or not. The documents may come from teaching and research institutions in France or abroad, or from public or private research centers.
L'archive ouverte pluridisciplinaire HAL, est destinée au dépôt et à la diffusion de documents scientifiques de niveau recherche, publiés ou non, émanant des établissements d'enseignement et de recherche français ou étrangers, des laboratoires publics ou privés. 
NOISE AND DIFFUSION IN P-TYPE SILICON

\author{
J.P. NOUGIER, A. MOATADID and J.C. VAISSIERE \\ Centre d'Electronique de Montpellier(1), Université des sciences et \\ Techniques du Languedoc, F-34060 Montpellier Cedex, France
}

RESUME: La théorie des fluctuations de la fonction d'occupation d'états, développée très récemment, et la notion de temps de relaxation différentiel, permettent de donner ici l'expression du coefficient de diffusion transversal, qui est calculé numériquement dans si-p en fonction du champ électrique a $300 \mathrm{~K}$ entre 0 et $50 \mathrm{kV} / \mathrm{cm}$.

ABSTRACT: The theory of the fluctuations of the state occupancy function, recently developped, together with the differential relaxation time, allow getting the transverse diffusion coefficient, which is computed in p-type Silicon, as a function of the electric field, at $300 \mathrm{~K}$, from 0 to $50 \mathrm{kV} / \mathrm{cm}$.

\title{
1. INTRODUCTION:
}

Except Monte Carlo simulations, which are much time consuming and thus very expensive, all the device modeling methods use transport equations, which require the knowledge of the diffusion coefficient $D(E)$ as a function of the electric field $E$. $D(E)$ is difficult to obtain. One way to get it is to study the diffusion noise, experimentally or theoretically. The purpose of this paper is to propose a new theoretical method for determining the diffusion coefficients, based on the differential relaxation time and on the fluctuation of the state occupancy function.

\section{STATE OCCUPANCY FUNCTION:}

In a previous paper [1], we settled a theory, derived from a series of nice papers from Gansevitch, Gurevitch and Katilius, they gathered in a review article [2]. In that paper, we studied the fluctuations of the State Occupancy Function $\mathrm{f}(\mathbf{k}, \mathrm{t})$ of hot carriers (labelled SOF in the following for convenience). $f(k, t)$ is a random function which takes the value 1 when the state $k$ is occupied by a carrier, and the value 0 when the state $\mathbf{k}$ is empty. The SOF depends on the external electric field $E$, but for convenience we shall omit $E$, wherever it is possible. $f(k, t)$ fluctuates, due to the random motion of the carriers. which undergo scattering events. If $\mathrm{N}(\mathrm{t})$ is the total number of carriers inside the sample at time $t$, one has :

$$
N(t)=\sum_{\mathbf{k}} f(\mathbf{k}, t)
$$

The ensemble average $\langle f(k, t)\rangle$ of $f(k, t)$ is then the distribution function at time $t$, governed by the Boltzmann equation (labelled $B E$ in the following). As $t \rightarrow \infty,\langle f(k, t)\rangle \rightarrow f_{s}(\mathbf{k}, E)$, solution of the steady state $\mathrm{BE}$ in the unifor $\mathrm{m}$ electric field $\mathrm{E}$.

\section{THE DIFFERENTIAL RELAXATION TIME:}

Since we intend to study small fluctuations around the steady state, we are interested in small deviations of the distribution function $\langle(\mathbf{f}, t)\rangle$ around its steady state value $f_{\mathbf{S}}(\mathbf{k}, E)$. This can be done

${ }^{(1)}$ Laboratoire Associé au CNRS, UA 391.

This study was partially supported by GCIS (Groupement Circuits Intégrés Silicium), France. 
using the differential relaxation time concept, introduced some years ago [3], defined as follows: When a small perturbation $\delta E$ is applied, the new steady state distribution is $f_{s}(k, E+\delta E)$. When the perturbation $\delta E$ is removed, $\langle f(k, t)\rangle$ evolves from $f_{s}(k, E+\delta E)$ to $f_{s}(k, E)$. The differential relaxation time $\tau(\mathbf{k}, E)$ is then defined as:

$$
\lim _{i \delta E \mid \rightarrow \infty}\left(\frac{\partial\langle f(\mathbf{k}, t)\rangle}{\partial t}\right)_{t=0}=-\lim _{|\delta E| \rightarrow \infty}\left(\frac{f_{S}(k, E+\delta E)-f_{S}(k, E)}{t(k, E)}\right)
$$

Indeed, as shown in [3], $\tau(\mathbf{k}, E)$ can be expressed, using the steady state $B E$ for $f_{\mathbf{s}}(\mathbf{k}, E+\delta E)$ and $f_{s}(k, E)$, and the transient $B E$ for $\langle f(k, t)\rangle$. One then finds that $\tau(k, E)$ depends on the direction of the perturbation $\delta \mathrm{E}$ with respect to the electric field $\mathbf{E}$ :

$$
\tau(\mathbf{k}, \mathrm{E})=-\frac{\hbar}{\mathrm{q}} \frac{\delta \mathrm{E} \cdot \nabla_{\mathrm{E}} \mathrm{f}_{\mathbf{S}}(\mathbf{k}, \mathbf{E})}{\delta \mathbf{E} \cdot \nabla_{\mathbf{L}} \boldsymbol{f}_{\mathbf{S}}(\mathbf{k}, \mathbf{E})}
$$

When $\delta \mathbf{E}$ is perpendicular to $\mathbf{E}$, one gets $\tau_{1}(\mathbf{k}, \mathbf{E})$. In polar coordinates with the polar axis along $\mathbf{E}$, $\mathbf{k}=\{k, \theta\}$ with $k=|k|$ and $\theta=(\mathbf{E}, \mathbf{k}), \tau_{1}(\mathbf{k}, E)$ is then easily expressed as $[3]$ :

$$
\tau_{\perp}(\mathbf{k}, E)=\frac{\hbar k}{q E} \frac{\partial f_{s}(\mathbf{k}, E) / \partial \theta}{\left(\partial f_{s}(\mathbf{k}, E) / \partial \theta\right) \cos \theta+k\left(\partial \mathrm{f}_{s}(\mathbf{k}, E) / \partial k\right) \sin \theta}
$$

Within the above hypothesis, the evolution of the distribution function $\langle(\mathbf{f}, t)\rangle$, around its steady state value $f_{s}(\mathbf{k}, E)$, is governed by the equation:

$$
\frac{\partial\langle\mathbf{f}(\mathbf{k}, t)\rangle}{\partial t}=-\frac{\langle f(\mathbf{k}, t)\rangle-f_{s}(\mathbf{k}, E)}{\tau(\mathbf{k}, E)}
$$

As an example, figure 1 shows the variations of $\tau_{1}(\mathbf{k}, E)$ versus $k=|k|$, along three directions with respect to the electric field $\mathbf{E}(\theta=0, \theta=\pi / 2$, and $\theta=\pi)$, in undoped $p$-type Silicon at $300 \mathrm{~K}, \mathrm{E}=2$ $\mathrm{kV} / \mathrm{cm}$ (fig. $1 \mathrm{a}$ ) and $\mathrm{E}=20 \mathrm{kV} / \mathrm{cm}$ (fig. $1 \mathrm{~b}$ ). $\mathrm{f}_{\mathbf{s}}(\mathbf{k}, \mathrm{E})$ was computed numerically, using a matrix method, so as $\tau_{\perp}(k, E)$ through eq. (4). We used a one spherical non parabolic band model. As can be seen fig.1, $\tau_{\perp}(k, E)$ is in the range 0.01 to 0.2 ps at $20 \mathrm{kV} / \mathrm{cm}$, and increases as the field strength decreases.

\section{FlUCtUATION OF THE STATE OCCUPANCY FUNCTION:}

In order to study the fluctuations of the SOF, we apply the general theory developped in [1], to the particular case studied here, where the $\mathrm{BE}$ is replaced by eq. (5). According to [1], one sets:

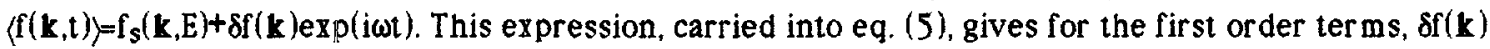
as a solution of:

$$
\left[i \omega+\frac{1}{\tau(\mathbf{k}, \mathrm{E})}\right] \delta \mathrm{f}(\mathbf{k})=0
$$

The Langevin theory then relies the fluctuation $\hat{f}(\mathbf{k}, \omega)$ to the white noise source term $\xi(\mathbf{k})$ by:

$$
\left[i \omega+\frac{1}{\tau(\mathbf{k}, E)}\right] \hat{f}(\mathbf{k}, \omega)=\xi(\mathbf{k})
$$


This gives, for the spectral density $S_{f}\left(\mathbf{k}, \mathbf{k}^{\prime}, \omega\right)$ of the fluctuations of the SOF:

$$
S_{f}\left(k, k^{\prime}, \omega\right)=\frac{\tau^{2}(\mathbf{k}, E)}{1+\omega^{2} \tau^{2}(\mathbf{k}, E)} S_{\xi}(\mathbf{k}) \delta_{\mathbf{k}} \mathbf{k}^{\prime}
$$

where $\delta_{\mathbf{k}} \mathbf{k}^{\cdot \mathbf{x}} 1$ if $\mathbf{k}=\mathbf{k}^{\cdot}$, and $\delta_{\mathbf{k}} \mathbf{k}^{\cdot} 0$ if $\mathbf{k} \neq \mathbf{k}^{\cdot} . S_{\xi}(\mathbf{k})$ can be evaluated using the variance $\left\langle\Delta f^{2}(\mathbf{k}, t)\right\rangle$ which writes [1]:

$$
\left\langle\Delta f^{2}(\mathbf{k}, t)\right\rangle=f_{s}(k, E)\left[1-f_{s}(\mathbf{k}, E)\right]=\int_{0}^{\infty} S_{f}(\mathbf{k}, \mathbf{k}, \omega) d v
$$

Carrying eq. $(8)$ in eq. $(9)$ readily gives $S_{\xi}(\mathbf{k})$, so that finally, with $F_{\mathcal{s}}(\mathbf{k}, E)=f_{\mathbf{s}}(\mathbf{k}, E)\left[1-f_{\mathbf{s}}(\mathbf{k}, E)\right]$ :

$$
S_{\mathrm{f}}\left(\mathbf{k}, \mathbf{k}^{\prime}, \omega\right)=\frac{4 \tau(\mathbf{k}, E)}{1+\omega^{2} \tau^{2}(\mathbf{k}, E)} F_{\mathrm{s}}(\mathbf{k}, E) \delta_{\mathbf{k}} \cdot
$$

\section{DIFFUSION COEFFICIENT:}

The spectral density $S_{j \omega \beta}(\omega)$ of the fluctuations of the current density writes [2][1]:

$$
S_{j \alpha \beta}(\omega)=\frac{q^{2}}{\Omega^{2}} \underset{\mathbf{k} \mathbf{k}^{\prime}}{\sum v_{\mathrm{u}^{\prime}}(\mathbf{k}) \mathrm{v}_{\beta}\left(\mathbf{k}^{\prime}\right) S_{\boldsymbol{\gamma}}\left(\mathbf{k}, \mathbf{k}^{\prime}, \omega\right)}
$$

where $\Omega$ is the volume of the sample, and $\alpha$ and $\beta$ mean directions with respect to the electric field. The local noise source term $K_{\alpha p}(\omega)$ is:

$$
K_{\alpha, \beta}(\omega)=\Omega S_{j \omega \beta}(\omega)=4 q^{2} \cap D_{\alpha \beta}(\omega)
$$

which gives, using eqs.(11) and (10), replacing summations over $\mathbf{k}$ by integrations over $\{\mathbf{k}$ \} space, and taking into account the density of states $1 / 8 \pi^{3}$ :

$$
D_{\alpha \beta}(\omega)=\frac{\frac{\tau(\mathbf{k}, E) v_{\alpha(}(k) v_{\beta}(k)}{1+\omega^{2} \tau^{2}(k, E)} F_{S}(k, E) d^{3} k}{\int f_{S}(k, E) d^{3} k}
$$

Using this method, we computed the transverse diffusion coefficient $D_{1}(E)$ in $p$-type Silicon, with doping impurity concentrations $\mathrm{N}_{\mathrm{A}}=0$ and $\mathrm{N}_{\mathrm{A}}=10^{17} \mathrm{~cm}^{-3}$, at $\mathrm{t}=300 \mathrm{~K}$, as a function of the electric field intensity $E$. Then, in eq. (13), $v_{s}(\mathbf{k})=v_{\beta}(\mathbf{k})=v \sin \theta \cos \varphi, \tau(\mathbf{k}, E)=\tau_{\perp}(\mathbf{k}, E)$ and $F_{\mathcal{s}}(\mathbf{k}, E) \approx f_{\mathbf{s}}(\mathbf{k}, E)$ since in our case the semiconductor is non degenerate. $D_{1}(E)$ was also computed using a Monte Carlo simulation. The results are shown figure 2: taking into account the statistical dispersion of the Monte Carlo simulation, the results are in excellent agreement.

The result presented here is the first theoretical determination of the hot carrier diffusion coefficient using the distribution function, with non randomizing scatterring mechanisms. Depending on the electric field strength, it is 10 to $50 \mathrm{CPU}$ time less consuming than the Monte Carlo simulation. 


\section{REPERENCES:}

[1] J.P. NOUGIER, J.C. VAISSIERE, Phys. Rev. B15, 8882 (1988)

[2] S.V. GANSEVITCH, V.L. GUREVITCH, R. KATILIUS, Rivista Nuovo Cimento, 2, 1 (1979)

[3] J.P. NOUGIER, M. ROLLAND, J. Appl. Phys. 48 , 1683 (1977)
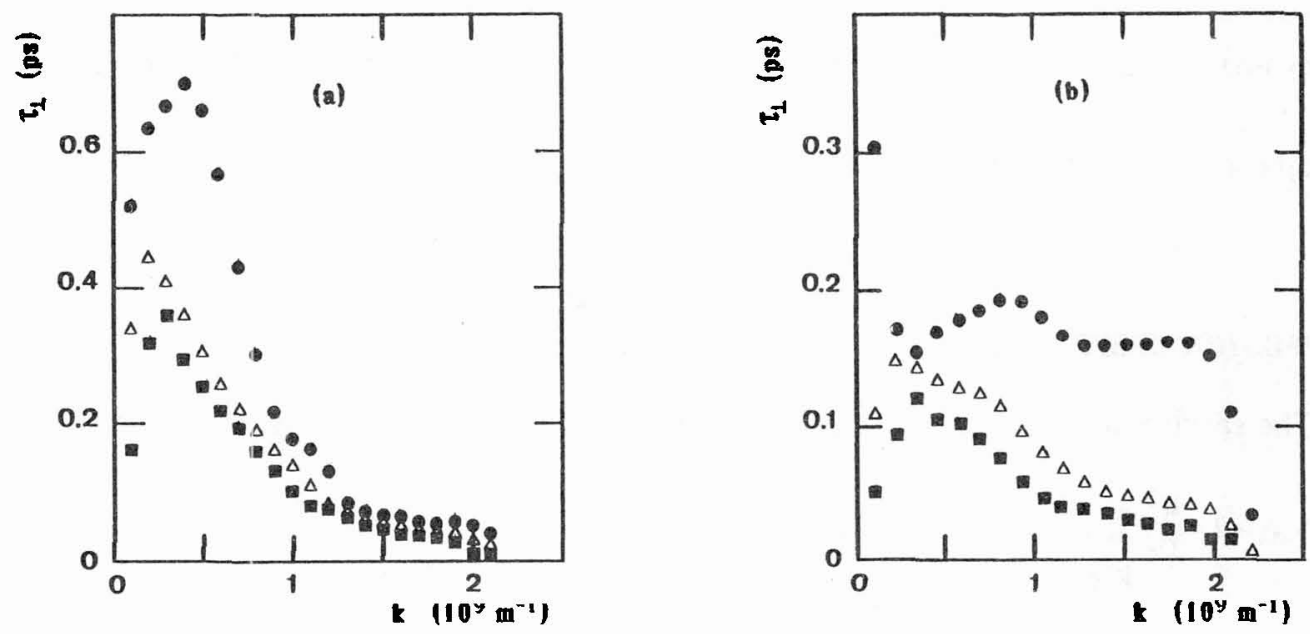

Figure 1: $\tau_{\perp}(k, E)$ for holes in undoped Silicon, as a function of $k=|k|$, at $300 \mathrm{~K}$, along three directions $\theta=0(\bullet), \theta=\pi / 2(\Delta)$, and $\theta=\pi(-)$, with respect to the electric field $\mathbf{E}$. (a) $\mathrm{E}=2 \mathrm{kV} / \mathrm{cm},(\mathrm{b}) \mathrm{E}=20 \mathrm{kV} / \mathrm{cm}$.

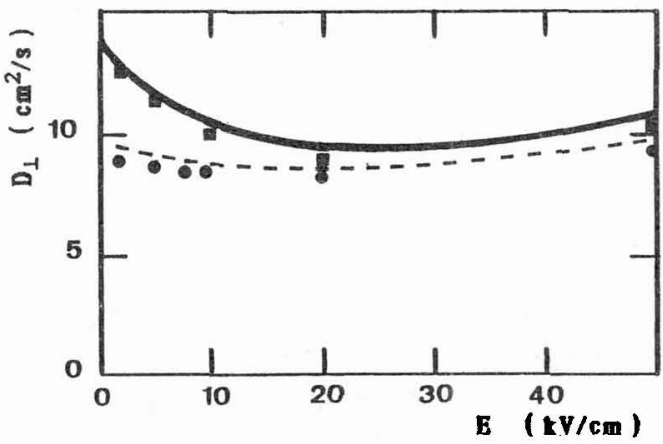

Figure 2: Transverse diffusion coefficient $D_{1}(E)$ of holes, as a function of the electric field intensity $E$, in pure $\left(\mathrm{N}_{\mathrm{A}}=0\right)$ and doped $\left(\mathrm{N}_{\mathrm{A}}=10^{17} \mathrm{~cm}^{-3}\right)$ p-type $\mathrm{Si}$ at $300 \mathrm{~K}$.

Monte Carlo simulation: $\mathrm{N}_{\mathrm{A}}=0(-)$ and $\mathrm{N}_{\mathrm{A}}=1017 \mathrm{~cm}^{-3}(----)$

Computed using eq. (13): $\mathrm{N}_{\mathrm{A}}=0(-)$ and $\mathrm{N}_{\mathrm{A}}=10^{17} \mathrm{~cm}^{-3}(\bullet)$ 